\title{
Intermittent Theta-Burst Stimulation of the Lateral Cerebellum Increases Functional Connectivity of the Default Network
}

\author{
(D) Mark A. Halko, ${ }^{1}$ Faranak Farzan, ${ }^{1,2}{ }^{\circledR}$ Mark C. Eldaief, ${ }^{1,3}$ Jeremy D. Schmahmann, ${ }^{4}$ and Alvaro Pascual-Leone ${ }^{1}$ \\ ${ }^{1}$ Berenson-Allen Center for Noninvasive Brain Stimulation, Beth Israel Deaconess Medical Center, Boston, Massachusetts 02215, ${ }^{2}$ Temerty Centre for \\ Therapeutic Brain Intervention, Centre for Addiction and Mental Health, University of Toronto, Toronto, Ontario, Canada M6J 1H4, ${ }^{3} \mathrm{Neurology}$, Brigham \\ and Women's Hospital, Boston, Massachusetts 02115, and ${ }^{4}$ Ataxia Unit, Cognitive and Behavioral Neurology Unit, Laboratory for Neuroanatomy and \\ Cerebellar Neurobiology, Department of Neurology, Massachusetts General Hospital, Boston, Massachusetts 02114
}

Cerebral cortical intrinsic connectivity networks share topographically arranged functional connectivity with the cerebellum. However, the contribution of cerebellar nodes to distributed network organization and function remains poorly understood. In humans, we applied theta-burst transcranial magnetic stimulation, guided by subject-specific connectivity, to regions of the cerebellum to evaluate the functional relevance of connections between cerebellar and cerebral cortical nodes in different networks. We demonstrate that changing activity in the human lateral cerebellar Crus I/II modulates the cerebral default mode network, whereas vermal lobule VII stimulation influences the cerebral dorsal attention system. These results provide novel insights into the distributed, but anatomically specific, modulatory impact of cerebellar effects on large-scale neural network function.

Key words: cerebellar hemispheres; cerebellum vermis; default mode network; functional connectivity; noninvasive brain stimulation; resting state

\section{Introduction}

The functions of the cerebellum were thought to be confined to motor control and thus that cerebellar lesions resulted exclusively in deficits of extremity coordination, balance, gait, clarity of speech, or eye movements. This view has been superseded by a more nuanced understanding of the role of the cerebellum in neurological and neuropsychiatric function. Patients with lesions of the cerebellar anterior lobe demonstrate findings of impaired

Received April 28, 2014; revised June 24, 2014; accepted July 14, 2014.

Author contributions: M.A.H., F.F., M.C.E., J.D.S., and A.P.-L. designed research; M.A.H., F.F., and M.C.E. performed research; M.C.E. contributed unpublished reagents/analytic tools; M.A.H. analyzed data; M.A.H., F.F., J.D.S., and A.P.-L. wrote the paper.

Work on this project is supported grants from the Sidney R. Baer Jr. Foundation and National Institutes of Health (NIH)/National Institutes for Neurological Disorders and Stroke Grant R21 NS085491. M.A.H. is supported by a KL2 Medical Research Investigator Training award (an appointed KL2 award) from the Harvard Catalyst/The Harvard Clinical and Translational Science Center (National Center for Research Resources and National Center for Advanced Translational Sciences/NIH Grant 8KL2TR000168-05). J.D.S. is supported in part by the Sidney R. Baer Jr. Foundation and the MINDlink and Birmingham Foundations. A.P.L. is supported by NIH Grants R01HD069776, R01NS073601, R21 MH099196, R21 NS082870, R21 NS085491, R21 HD07616, and UL1 RR025758, the Michael J. Fox Foundation, and the Sidney R. Baer Foundation. We are grateful for the assistance of Ned Gold, Rain Thomas, Carrie Hinchman, and Sam Rendall for collecting this data, Mike Fox for helpful discussions, and Stephanie McMains and the staff of the Harvard Center for Brain Science for assistance in collecting and analyzing the data.

Dr. Pascual-Leone serves on the scientific advisory boards for Nexstim, Neuronix, Starlab Neuroscience, Neuroelectrics, and Neosync and is listed as an inventor on several issued and pending patents on the real-time integration of transcranial magnetic stimulation with electroencephalography and magnetic resonance imaging. Dr. Schmahmann serves as a consultant to Takeda Pharmaceuticals.

Correspondence should be addressed to Dr. Mark A. Halko, Berenson-Allen Center for Noninvasive Brain StimuIation, Beth Israel Deaconess Medical Center and Harvard Medical School, 330 Brookline Avenue, E/KS 158, Boston, MA 02215.E-mail:mhalko@bidmc.harvard.edu.

DOI:10.1523/JNEUROSCI.1776-14.2014

Copyright $\odot 2014$ the authors $\quad 0270-6474 / 14 / 3412049-08 \$ 15.00 / 0$ movement control, whereas those with lesions confined to the cerebellar posterior lobe do not develop motor deficits but rather a constellation of problems in higher-order functions conceptualized as the cerebellar cognitive affective syndrome (Schmahmann and Sherman, 1998; Stoodley et al., 2010).

As in the cerebral hemispheres, the network nodes in the cerebellum are topographically arranged (Buckner et al., 2011). The default mode network was assigned multiple different locations in the cerebellum in early studies (Fox et al., 2005; Habas et al., 2009), but larger sample datasets have been able to define the cerebellar default network nodes more clearly within Crus I and Crus II of the cerebellar hemispheres (Krienen and Buckner, 2009; Buckner et al., 2011). The locations of the spontaneous activity correlations observed in the cerebellum and the cerebral cortex reflect known cerebro-cerebellar anatomical connections, such that, when lesions disrupt anatomical connectivity, functional connectivity is also lost (Lu et al., 2011). Thus, the cerebellar nodes of cortical networks are likely actively involved in network function.

We have shown previously that functional connectivity can be altered between the site of stimulation and other network nodes (Eldaief et al., 2011). This modulation was dependent on the frequency of stimulation, demonstrating a dose dependence of the effect. Transcranial magnetic stimulation (TMS) to a single region may not change connectivity between regions but rather only change the activity in a single location, which is reflected in the connectivity measurement between regions. Alternatively, TMS to a single region may alter functional connectivity within 
the whole network, secondary from effects to the stimulated target. The previous cortical stimulation demonstrated changes between the stimulated site and additional network nodes but could not establish network-wide changes (Eldaief et al., 2011).

Here we explore whether stimulation of a network node is spatially specific and can spread beyond stimulated connections to affect distributed network activity. We examined the topography of network modulation by stimulating the right cerebellar node of the default network with intermittent theta-burst stimulation (iTBS) TMS (Fig. 1) and compared the changes in network connectivity to the changes resulting from cerebellar midline (vermis) stimulation and sham stimulation within the same healthy participants. Right lateral cerebellar stimulation was localized with functional connectivity before stimulation, midline stimulation targeted lobule VII of the cerebellar vermis, and sham stimulation was delivered using a specially designed sham coil that replicates the perception of active TMS. Nine participants were scanned using resting-state imaging in three separate experimental sessions during which they received neuronavigated TMS to the lateral cerebellum, the midline cerebellum, or sham stimulation and thereafter immediately returned to the MRI to assess changes in their resting-state connectivity patterns.

\section{Materials and Methods}

Participants. Ten healthy human participants were recruited for this study from the local Boston area. All participants gave informed consent in accordance with the guidelines of the Committee on Clinical Investigations at Beth Israel Deaconess Medical Center. One participant reported feeling nauseous after midline stimulation and was withdrawn from the study. Thus, data from nine participants (four females) are reported.

MRI acquisition. All MR imaging was conducted at the Center for Brain Science at Harvard University using a 3T Tim Trio MRI (Siemens). At the beginning of each TMS resting-state functional connectivity MRI session, a multi-image MPRAGE anatomical image was acquired $\left(1 \mathrm{~mm}^{3}\right.$ voxels, $2.53 \mathrm{~s}$ TR, $1.64 \mathrm{~ms}$ TE, $1200 \mathrm{~ms}$ inversion time, acceleration factor of 2), and then three 6 min BOLD contrast EPI sequence resting-state runs were collected $\left(3 \mathrm{~mm}^{3}\right.$ voxels, $3 \mathrm{~s}$ TR, $30 \mathrm{~ms}$ TE, $90^{\circ}$ flip angle, 47 axial slices). Participants were then removed from the scanner and taken to a TMS room near the scanner. After TMS, subjects were put back in the scanner, a short localizer was run, and then three 6 min resting-state runs were collected. After the resting-state scans, a second multi-image MPRAGE was collected for alignment purposes for the post-TMS scans. During the resting-state runs, participants were asked to keep their eyes open and fixate a large white dot on a black background projected on a screen in the rear of the MRI bore. Participants were given the following instructions: "Keep your eyes open, stare at the dot, think about whatever comes to mind, and don't move." No systemic differences were observed in elapsed time between end of stimulation and start of first functional run (all $p>0.25$ ). The mean time to the first functional scan was $4 \mathrm{~min}, 15 \mathrm{~s}$.

TMS. All TMS was performed using a MagPro X100 with MagOption (MagVenture), coupled with a Brainsight neuronavigation system with an MEP pod (Rouge Research). Each participant's resting and active motor threshold was measured on the first dorsal interosseous muscle using PowerLab (ADInstruments). Motor stimulation was delivered to the left hemisphere and measured on the right hand using a C-B60 figure-of-eight coil (MagVenture). iTBS was performed in which 10 bursts of high-frequency stimulation (three biphasic waveform pulses at $50 \mathrm{~Hz}$ ) are applied at $5 \mathrm{~Hz}$, every $10 \mathrm{~s}$ for 600 total pulses (Huang et al.,
2005). Cerebellar TMS was delivered at 100\% of active motor threshold intensity (Demirtas-Tatlidede et al., 2010). TMS was delivered using a Cool-B65 AP figure-of-eight coil (MagVenture), which can be used in either active or sham mode. The coil was oriented vertically, along the superior-posterior plane of the neck, with the handle facing upward for all stimulations. During all stimulations, real or sham, two shamming electrodes were placed near the subject's hairline near the stimulation location. These electrodes simulate some of the TMS experience by creating twitches in synchronization with the sham stimulation. All participants were blind to the experimental condition, and condition order was randomized across subjects. Experimenters were not blind to the stimulation condition. Two cerebellar targets were selected. The right cerebellar node of the default network was functionally localized using resting-state imaging in each subject, by using a precuneus seed from a previous session. A target was placed in cerebellar cortex nearest the center of largest connectivity in the lateral cerebellum, which was always in Crus I or Crus II (mean MNI: 41, $-72,-39$ ). The second target was based on previous literature describing vermis cerebellar stimulation (Demirtas-Tatlidede et al., 2010). This target was placed in lobule VII (according to Schmahmann et al., 2000) in the midline cerebellum, determined anatomically from a previous MRI session (mean MNI: 1, -73, $-33)$. No systematic differences were observed in stimulation amplitude across conditions. All sessions were separated by a minimum of $48 \mathrm{~h}$ to avoid carryover effects.

Functional connectivity MRI data analysis. All analysis was performed using previously described techniques (Halko et al., 2010; Eldaief et al., 2011). Briefly, resting-state fMRI data were preprocessed: spatial normalization to the standard MNI152 template, slice-timing correction, and motion correction. A second preprocessing stage removed nuisance variables (global mean signal, motion, white matter, and CSF) and spatiotemporally smoothed the data $(>0.08 \mathrm{~Hz}, 7 \mathrm{~mm}$ FWHM). After preprocessing, region-of-interest "seeds" were used as masks to extract a mean time course for a seed. This mean time course was then correlated against all voxels in the brain to compute a functional connectivity map to the original seed. Time courses from a priori selected seed regions were extracted and then correlated. All correlations were then $z$-transformed using Fisher's $r$-to- $z$ transformation for subsequent statistical analysis. Seed regions were individually localized based on same-subject restingstate data. For default network analysis, the entire default network of the seven network parcellation nodes from the study by Yeo et al. (2011) was used as a single seed to generate a network map, individualized to the subject. This map was computed for pre-TMS visits on the other days (e.g., to estimate network connectivity from lateral stimulation day, preTMS connectivity from the sham and midline stimulation sessions were used to create individual seed maps). These maps were then thresholded, and then individual clusters were selected using the default network map. Thus, to identify an individual subject's left inferior parietal lobule (LIPL) default network node for lateral stimulation, the Yeo average default network map was used as a seed to generate functional connectivity maps from pre-TMS sham and pre-TMS midline sessions. These sessions were then averaged together, thresholded, and then multiplied by an inflated mask of the LIPL node in the Yeo average map. The resultant seed is an LIPL node, derived from an independent measure of the individuals own intrinsic connectivity pattern. This seed was indepen- 


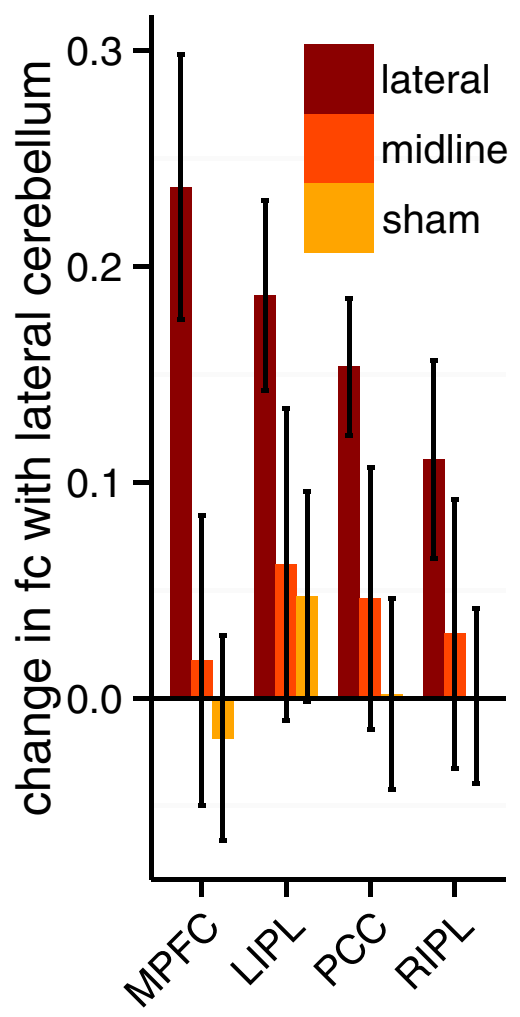

Figure 2. Change in functional connectivity (fc) between cerebellum target and default network nodes. Difference of $z$-transformed Pearson's $r$ correlation coefficients before and after stimulation. Error bars indicate SEM.

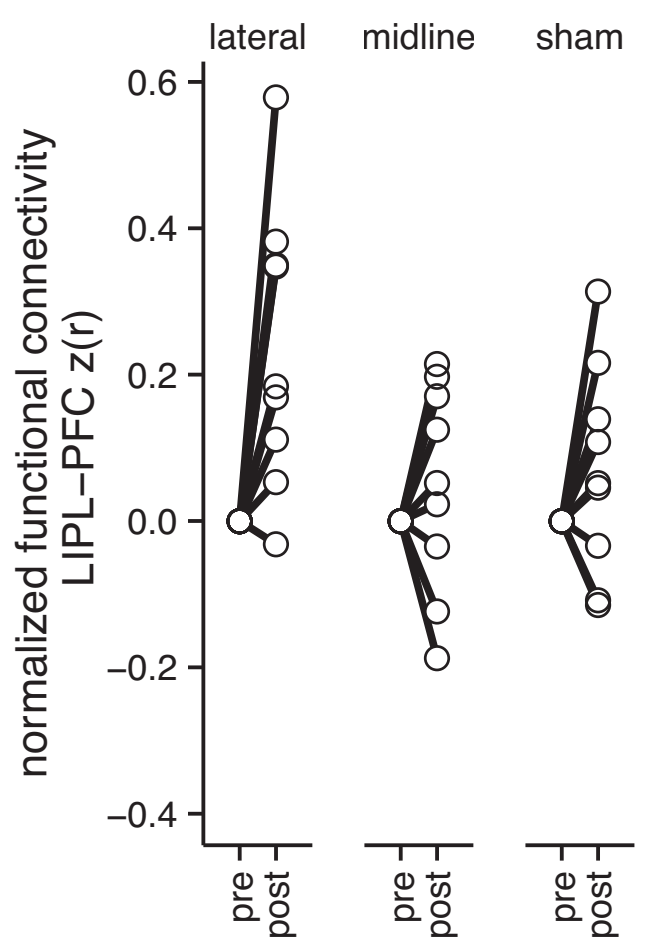

Figure 4. Changes in default network functional connectivity after each stimulation condition, normalized to individual pre-TMS functional connectivity. Functional connectivity was computed between the LIPL and the MPFC as z-transformed Pearson's correlation coefficients. Increased functional connectivity is evident in the lateral case but not in either control condition.

dently created for every session (e.g., midline stimulation was derived from lateral and sham, sham stimulation was derived from lateral and midline). The same seeds were used to compare pre-TMS to post-TMS within each individual. Uncorrected $t$ statistic maps were generated to give an overview of the voxelwise pattern of statistical change. Regionof-interest analysis was performed on expected main effects within the core default network: precuneus/posterior cingulate cortex (PCC), medial prefrontal cortex (MPFC), LIPL, and right IPL (RIPL), as well as the stimulated right cerebellar default network node. All ANOVAs were tested for homogeneity of variance using the Fligner-Kileen test and were not found to violate the assumption of homogeneity.

\section{Results}

iTBS TMS to the default network cerebellum node increases functional connectivity within the cerebral cortical default network

If the cerebro-cerebellar functional connectivity observed at rest has a causal affect on the cerebral corticocortical network functional connectivity, then TMS to the cerebellum should change functional connectivity between the cerebellum and cerebral cortical locations. To investigate this hypothesis, we compared functional connectivity between the right lateral cerebellum default network target and the default network: PCC, mPFC, LIPL, and RIPL before and after each stimulation condition. Each $z$-transformed Pearson's correlation coefficient difference (post - pre) was entered into a two-way ANOVA to compare the effect of TMS target and seed location. A significant effect of TMS target was found $\left(F_{(2,96)}=10.61, p<0.001\right)$. No effect of seed location was found $\left(F_{(3,96)}=0.483, p=0.695\right)$. No interaction between seed location and TMS target was found $\left(F_{(6,96)}=0.455, p=0.84\right)$. Post hoc Tukey's HSD test found a significant difference in change in functional connectivity for lateral cerebellar stimulation over sham stimulation $(p<0.001)$
Figure 3. Change in functional connectivity ( $f c$ ) between cortical default network nodes. Difference of z-transformed Pearson's $r$ correlation coefficients before and after stimulation. Error bars indicate SEM. 

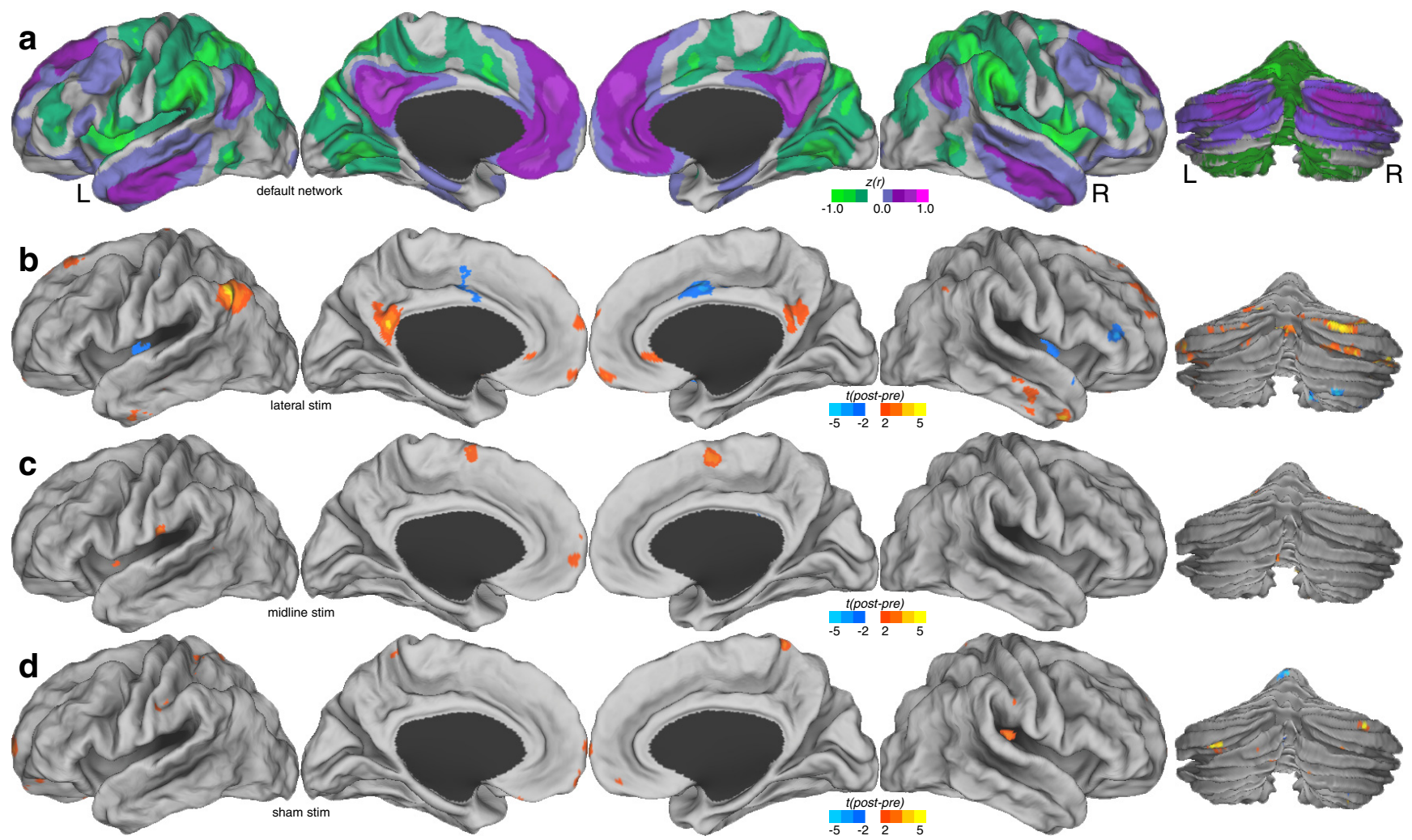

Figure 5. Voxelwise map of changes before and after stimulation in the default network across experimental conditions. $\boldsymbol{a}$, Mean baseline functional connectivity (z-transformed Pearson's correlation coefficients) of the default network. $\boldsymbol{b}, t$ statistic of change in functional connectivity for lateral stimulation sessions. $\boldsymbol{c}, t$ statistic of change in functional connectivity for midline stimulation. $\boldsymbol{d}, t$ statistic of change in functional connectivity for sham stimulation. L, Left; $R$, right.

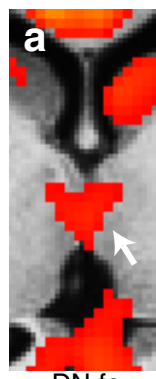

$\overline{D N} \mathrm{fc}$
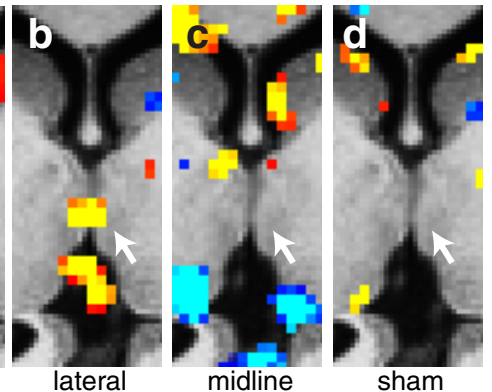

Figure 6. Voxelwise map of changes of the default network functional connectivity (fc) in the thalamus. $\boldsymbol{a}$, Mean baseline functional connectivity (z-transformed Pearson's correlation coefficients) of the default network. $\boldsymbol{b}, t$ statistic of change in functional connectivity for lateral stimulation sessions. $\boldsymbol{c}, t$ statistic of change in functional connectivity for midline stimulation. $\boldsymbol{d}$, $t$ statistic of change in functional connectivity for sham stimulation.

and midline stimulation $(p=0.002)$ but no difference between sham and midline stimulation ( $p=0.69$; Fig. 2 ).

To evaluate the core hypothesis, that cerebellar stimulation will change corticocortical functional connectivity, we examined region-to-region connectivity within regions of cortical default network (PCC, MPFC, RIPL, LIPL). A significant effect was found for TMS target $\left(F_{(2,144)}=16.479, p<0.001\right)$. A significant effect was also found for seed location $\left(F_{(5,144)}=3.029, p=\right.$ 0.012 ), and no effect was found for the interaction between stimulation session and location $\left(F_{(10,144)}=0.605, p=0.81\right)$. Post hoc tests revealed the seed-to-seed change from LIPL to RIPL and from RIPL to PCC created the effect of seed location because it was not affected in the lateral stimulation condition, but no seed pair was significantly different from each other in corrected post hoc tests (all $p>0.05$ ). Post hoc tests showed significant increases in functional connectivity for lateral stimulation compared with sham $(p<0.001)$ and midline $(p<0.001)$ stimulation. We also found a difference between midline stimulation and sham $(p<$ 0.001 ), but this difference did not survive when the RIPL seeds above were removed from the model ( $p=0.47$; Fig. 3). Individual subject differences are shown in Figure 4.

To confirm the finding of region-to-region increases in functional connectivity, we performed a voxelwise comparison test of default network functional connectivity before and after stimulation (Fig. 5). These maps demonstrate the location specificity of the stimulation of the cerebellum on default network modulation. Functional connectivity within the default network was altered only in the lateral cerebellum condition (targeting the cerebellar default network node). No default network changes are apparent as a result of midline cerebellum stimulation or from sham stimulation, even when examining uncorrected $t$ statistic images.

Feedback projections from the cerebellum to the cerebral cortex are conveyed from the deep cerebellar nuclei, principally the dentate nucleus, to terminate in thalamus from where they are then conveyed to the cerebral cortex (Brodal, 1981). Therefore, it would be expected that stimulation of the default network at the right lateral node of the cerebellum would also affect thalamic connectivity. When the voxelwise analysis is applied to the thalamus, only lateral cerebellar stimulation alters default network connectivity within the thalamus (Fig. 6).

Midline cerebellar stimulation was found to not alter default network functional connectivity. This suggests that cerebellar TMS has sufficient functional resolution to affect nodes of individual networks within the cerebellum. Similarly, no effects were 

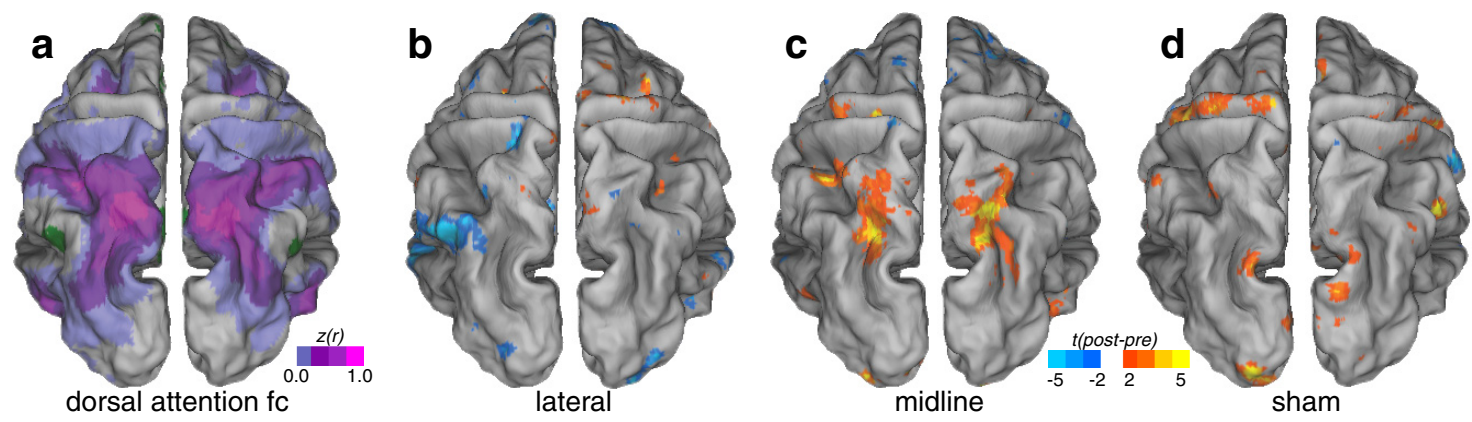

Figure 7. Voxelwise map of changes before and after stimulation in the dorsal attention network across experimental conditions. $\boldsymbol{a}$, Mean baseline functional connectivity (fc) ( $z$-transformed Pearson's correlation coefficients) of the default network. $\boldsymbol{b}, t$ statistic of change in functional connectivity for lateral stimulation sessions. $c, t$ statistic of change in functional connectivity for midline stimulation. $\boldsymbol{d}$, $t$ statistic of change in functional connectivity for sham stimulation.

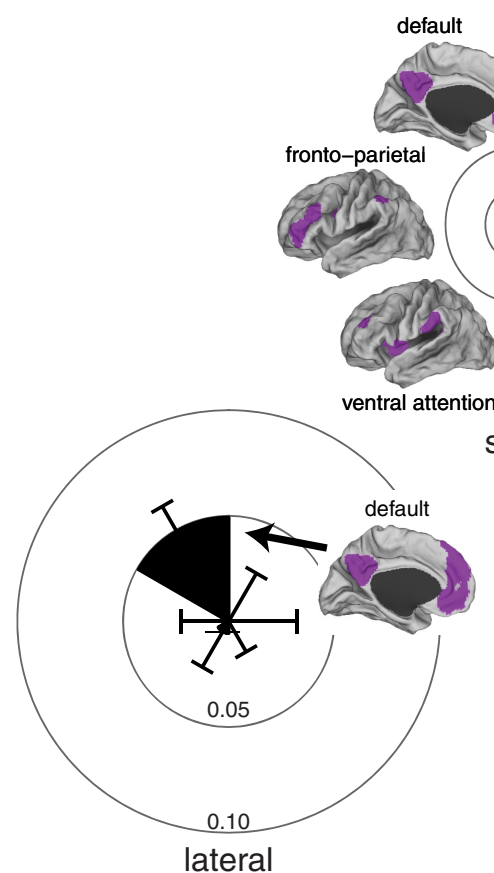

Figure 8. Changes in other functional networks after stimulation. The networks of Yeo et al. (2011) were used to create a single time course for each network, and then all voxels from within those networks were correlated to the mean network time course. Positive changes in network connectivity were plotted on a radial histogram to demonstrate the specificity of stimulation within the default network. Error bars reflect the SEM difference.

observed in the default network arising from sham stimulation (Fig. 7).

TMS to network nodes is spatially specific: midline stimulation increases the dorsal attention network but not the default network

The midline stimulation site served as a control to demonstrate the specificity of focal cerebellar stimulation on the default network. The midline cerebellum targets are part of a different cortical network organization that thus may be similarly upregulated by cerebellar stimulation. The cerebellum midline contains a number of network nodes, both deep within the cerebellar vermis and superficial along the medial cerebellar lobes, the most posterior and medial of which is the dorsal attention network (Buckner et al., 2011). To test the secondary and exploratory hypothesis that midline stimulation upregulates a different network, we examined the affect of TMS on the dorsal attention network, comparing the change in mean network functional connectivity in two networks (default network and dorsal attention network) across the three stimulation conditions (lateral, midline, and sham). A two-way ANOVA revealed a significant interaction $\left(F_{(2,48)}=3.56, p=0.036\right)$ but no significant main effects of stimulation condition $\left(F_{(2,48)}=1.11, p=0.33\right)$ or network $\left(F_{(1,48)}=0, p=0.98\right)$. Removal of the sham session from the analysis revealed the same interaction $\left(F_{(1,32)}=12.8, p=\right.$ $0.001)$ and no main effect of network $\left.F_{(1,32)}=0, p=0.99\right)$ or stimulation condition $\left(F_{(1,32)}=3.21, p=0.082\right)$. The default network was modulated in the lateral cerebellar stimulation session $\left(t_{(8)}=3.61\right.$, $p=0.028$ corrected) but not the midline cerebellar stimulation session $\left(t_{(8)}=1.15\right.$, $p=0.28$ uncorrected). Conversely, the dorsal attention system was modulated in the midline cerebellar stimulation session $\left(t_{(8)}=4.02, p=0.015\right.$ corrected) but not the lateral cerebellar stimulation session $\left(t_{(8)}=-0.65, p=0.53\right.$ uncorrected $)$. This difference appeared to be localized to superior parietal locations when examined with voxelwise maps (Fig. 7).

Subsequent exploratory analysis of additional networks revealed that the observed effects of stimulation conditions are primarily limited to the default network in the lateral stimulation and the dorsal attention network in the midline stimulation (Fig. 8).

\section{iTBS TMS to the lateral posterior cerebellum and vermal lobule VII does not alter motor connectivity}

The organization of cerebellar functional connectivity suggests that nodes sharing connectivity with nonmotor cortical sites outnumber those sharing connectivity with motor cortical sites and that the nonmotor representations may be more easily assessable via TMS (Buckner et al., 2011). If the targeted locations indeed are nonmotor, then no change should be observed in functional connectivity between primary motor cortex or within the entire motor system. Thus, a secondary analysis was performed to examine the effect of cerebellar TMS on the motor cortex. Within the entire motor network, no changes in functional connectivity were observed after lateral or midline cerebellar stimulation (midline, $t_{(8)}=1.59, p=0.15$; lateral, $t_{(8)}=-0.21, p=0.84$, all uncorrected). Because localized effects may have been observed, 

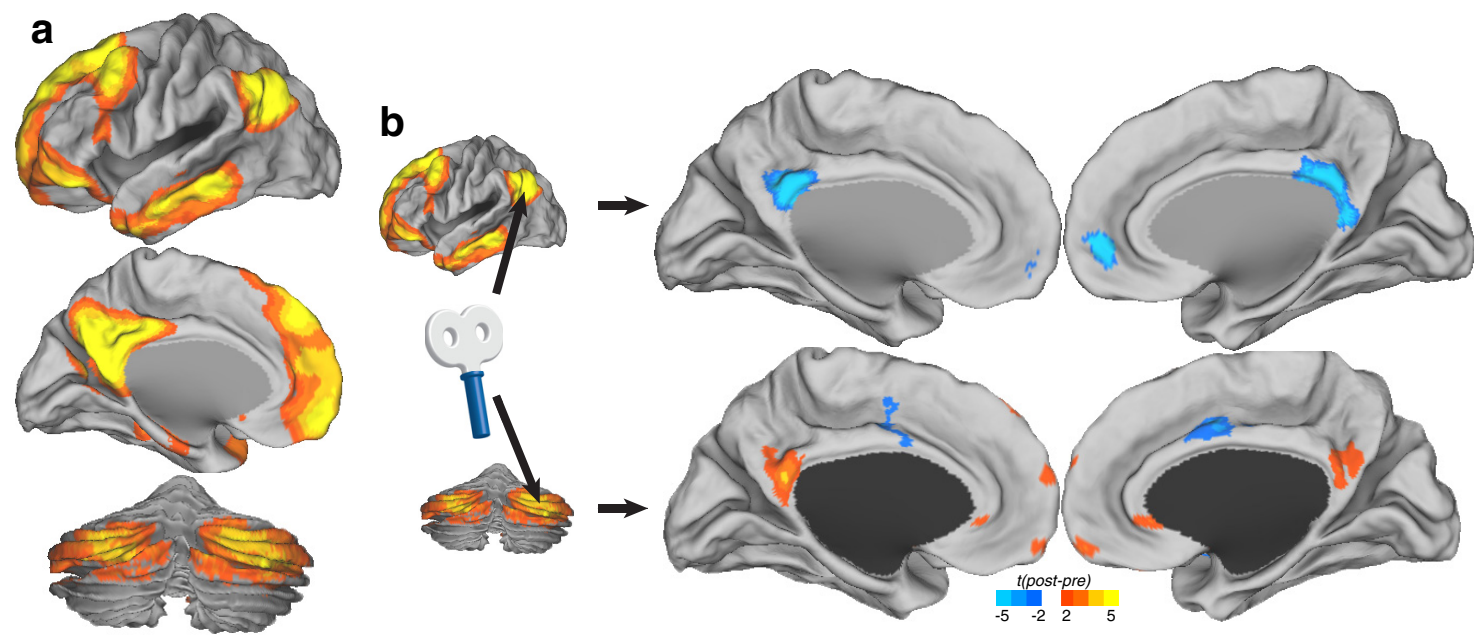

Figure 9. Comparison of cortical stimulation and cerebellar stimulation effects. $\boldsymbol{a}$, The default network, including the cerebellum. $\boldsymbol{b}$, Comparison of default network stimulation site effects. High-frequency stimulation to the LIPL reduces functional connectivity within the default network (modified from Eldaief et al. 2011), whereas iTBS to the cerebellum default network node increases functional connectivity within the default network. All analyses were performed using a default network mask as functional connectivity seed (blue, decreases in functional connectivity; red, increases in functional connectivity).

spherical seeds were placed in the hand representation of left and right primary motor cortex ( $6 \mathrm{~mm}$ radius; MNI: $\pm 41,-20,62)$. No significant difference was observed from cerebellar stimulation (midline, $t_{(8)}=-0.21, p=0.36$; lateral, $t_{(8)}=0.07, p=0.94$ all uncorrected). Additional voxelwise analysis revealed no additional change in the motor network.

\section{Discussion}

In this study, we demonstrate for the first time that it is possible to acutely modulate cerebral cortical nonmotor resting networks by targeting the cerebellum. When the right cerebellar node of the default network is targeted with iTBS, functional connectivity within cortical nodes of the default network is increased. This was not found when the cerebellar midline was targeted, nor when sham stimulation was applied. In fact, we were able to show a double dissociation, with lateral cerebellar stimulation affecting connectivity of the cortical default network whereas midline cerebellar stimulation affected connectivity in the cortical dorsal attention network, and neither affected motor network connectivity. This is the first demonstration of location specificity of network modulation by TMS.

Furthermore, we demonstrate that stimulation of a single node has distributed impact on an entire network. By stimulating the cerebellar default network node, connectivity within the cerebral cortical default network was affected.

\section{Cerebellar modulation of cortical networks}

This is the first study to demonstrate that cerebellar stimulation can be used to modulate cerebral cortical network functional connectivity. Previous studies have examined the role of cortical stimulation on cortical functional connectivity (Halko et al., 2010; van der Werf et al., 2010; Vercammen et al., 2010; Eldaief et al., 2011; Chen et al., 2013; Gratton et al., 2013; Watanabe et al., 2014). Some previous studies have not used individual functional connectivity to map a target location before stimulation (van der Werf et al., 2010; Vercammen et al., 2010) or have targeted cortical regions with high intersubject variability in connectivity (Chen et al., 2013; Gratton et al., 2013). We demonstrated previously that it is possible to reduce functional connectivity within the default network with high-frequency repetitive TMS (rTMS;
Eldaief et al., 2011). Here, using iTBS to the cerebellum, we show that the default network connectivity can be increased. A graphical comparison between these previous results and the present observations is shown in Figure 9. Additional investigation into this effect is indicated to determine whether the local effects of rTMS on the cortex differ compared with the cerebellum or arise from differences in anatomical connectivity between the cerebellum and cortex compared with cortical connections. We demonstrate that, by targeting different regions of the same network with similar types of stimulation, upmodulation or downmodulation of network activity can be obtained.

Our findings are consistent with neuroplastic effects within motor cortex from noninvasive brain stimulation (for review, see Grimaldi et al., 2014). TMS to lateral locations within the cerebellum has been demonstrated to have an effect on motor circuits (Koch et al., 2008). iTBS, as used in the present study, when directed to presumed portions of the motor cerebellum increases the amplitude of motor-evoked potentials and decreases long intracortical inhibition, which implicates the involvement of $\mathrm{GABA}_{\mathrm{B}}$ interneurons in motor cortex (Koch et al., 2008). These findings suggest that cerebellar stimulation will affect cortical circuitry and not just cerebellar-dependent function.

\section{Network specificity of rTMS}

The stimulation of two different sites within the cerebellum has two independent network effects: the lateral cerebellum affected the default network, and the midline cerebellum affected the dorsal attention network. Previously, we demonstrated that it was possible to dissociate different subnetworks of the default network by stimulating the same region with different frequencies of rTMS (Eldaief et al., 2011). Others have demonstrated diffuse effects of TMS between networks (Chen et al., 2013; Gratton et al., 2013). Our finding shows that the TMS impact remains within the targeted network. Although the stimulation locations are within a few centimeters, it is possible to dissociate stimulation effects on the cortical networks, revealing the functional resolution of noninvasive brain stimulation.

We observed that midline cerebellar stimulation upregulates connectivity in parietal areas of the dorsal attention system. The midline cerebellum includes a representation regarded as the ver- 
mal oculomotor system (Voogd et al., 2012), which receives anatomical projections from the lateral intraparietal area and frontal eye fields (Robinson and Fuchs, 2001; Prevosto et al., 2010). Electrical stimulation of these regions in the macaque results in saccadic and pursuit eye movements (Krauzlis and Miles, 1998). Lesions of the cerebellar vermis in humans produce smooth pursuit deficits (Baier et al., 2009), and single pulses of TMS to the vermis disrupt eye movements (Hashimoto and Ohtsuka, 1995). Midline cerebellar stimulation has also been noted to alter paced finger tapping, a visual-attentional task (Théoret et al., 2001), described previously as altering cerebellar timing circuits, but the present findings suggest an alternative interpretation of an altered visuospatial attentional system. Likewise, visual motion task performance can be affected by midline cerebellar stimulation (Cattaneo et al., 2014). Thus, the finding in the parietal cortex is consistent with cerebellar influence on visual attention (Allen et al., 1997).

TMS to the cerebellum, while mediating motor function, has also demonstrated effects on cognitive, memory, and perceptual functions (Desmond et al., 2005; Pastor et al., 2006), as well as nonsomatic functions (Demirtas-Tatlidede et al., 2011). A recent fluorodeoxyglucose-positron emission tomography study (Cho et al., 2012) also found cortical metabolic changes after lowfrequency stimulation of lateral cerebellum. Critically, our study differs from that of Cho et al. (2012) in that we specifically targeted the default network node within the cerebellum using neuronavigation rather than using a scalp-based anatomical landmark ( $1 \mathrm{~cm}$ inferior and $3 \mathrm{~cm}$ lateral to the inion). This particular location has been shown, using continuous theta burst (a suppressive TMS protocol), to affect motor circuits (Koch et al., 2008). Our study suggests that by mapping the functional topography of individual subjects, specific cortical networks may be targeted - and the impact of the stimulation on behavior can be better understood.

\section{A cerebellar default network node}

Altering default network connectivity via the node located in Crus I/II of the cerebellum is the first demonstration that the cerebellum plays an active role in shaping the cerebral cortical default network. Many reports of large-scale network function have understated cerebellar activity. Indeed, the first mention of a cerebellar default network node was by Fox et al. (2005) and was not fully investigated until Habas et al. (2009) did so and was finally located in the lateral hemispheres of the cerebellar posterior lobe by Buckner et al. (2011), despite the earliest description of the default network by Raichle et al. (2001). We demonstrate that TMS to a lateral region of the cerebellum in Crus I/II with increased functional connectivity to the default network affects cerebral cortical network functional connectivity. Previous studies have discussed alternate or additional cerebellar locations of node(s) of the default network: within the cerebellar tonsils (Fox et al., 2005) or lobule IX of the vermis (Habas et al., 2009). It is possible that these other locations may also be causally linked to the default network. Our finding establishes membership of the lateral cerebellar region in Crus I/II within the default network by providing a mechanism to modulate the cerebral cortical structures of the default network.

The presence of network nodes within the cerebellum with functional connectivity correspondence to cortical networks has been demonstrated recently to be topographically organized (Habas et al., 2009; O'Reilly et al., 2010; Buckner et al., 2011; Dobromyslin et al., 2012). These resting-state observations have corroborated polysynaptic tracing studies (for review, see
Schmahmann, 1991; Schmahmann and Pandya, 1997; Strick et al., 2009), showing nonmotor organization within the cerebellum. Since the early work by Snider and colleagues (Snider and Stowell, 1946; Snider, 1950; Snider and Eldred, 1951), it has been recognized that sensory and motor input to the cerebellum represents only a portion of the cerebellar topography in animals. The microstructure of the cerebellum remains similar regardless of location within the cerebellar cortex. As a result of this organized topography and the similarity of function within the motor system, it is reasonable to hypothesize that these network nodes serve an important function in modulating or mediating network activity (Schmahmann, 2004). We demonstrate that TMS appears to have sufficient specificity to manipulate connectivity between cerebral network nodes. Additional investigation would be necessary to determine how the cerebellum modulates network function and the subsequent implications of network modulation on cognition.

\section{Potential of network-based TMS therapy}

Functional connectivity within the default network is reduced in a number of psychiatric and neurological illnesses (Fox and Greicius, 2010; Zhang and Raichle, 2010). This is exemplified by the default network connectivity, which is reduced in Alzheimer's disease, reflecting pathological changes (Sperling et al., 2009; Sheline and Raichle, 2013), and appears to serve as an early biomarker of disease (Chhatwal et al., 2013). Therefore, it is conceivable that TMS could be used as a therapeutic intervention in this context, similar to the treatment of medication-resistant depression (Pascual-Leone et al., 1996; O'Reardon et al., 2007), targeting the cerebellum to modify cortical network dynamics. When the underlying network dynamics of disease are understood, novel network-based therapies can be developed. Similarly, other network abnormalities, such as those observed within schizophrenia, may be mediated via cerebellar stimulation (DemirtasTatlidede et al., 2010). With a better understanding of how brain stimulation affects cortical networks, there is realistic hope that we can create novel therapeutics to target network deficits.

\section{References}

Allen G, Buxton RB, Wong EC, Courchesne E (1997) Attentional activation of the cerebellum independent of motor involvement. Science 275:19401943. CrossRef Medline

Baier B, Stoeter P, Dieterich M (2009) Anatomical correlates of ocular motor deficits in cerebellar lesions. Brain 132:2114-2124. CrossRef Medline

Brodal A (1981) Neurological anatomy in relation to clinical medicine, Ed 3. New York: Oxford UP.

Buckner RL, Krienen FM, Castellanos A, Diaz JC, Yeo BTT (2011) The organization of the human cerebellum estimated by intrinsic functional connectivity. J Neurophysiol 106:2322-2345. CrossRef Medline

Cattaneo Z, Renzi C, Casali S, Silvanto J, Vecchi T, Papagno C, D’Angelo E (2014) Cerebellar vermis plays a causal role in visual motion discrimination. Cortex. Advance online publication. Retrieved July 21, 2014. doi: 10.1016/j.cortex.2014.01.012. CrossRef Medline

Chen AC, Oathes DJ, Chang C, Bradley T, Zhou ZW, Williams LM, Glover GH, Deisseroth K, Etkin A (2013) Causal interactions between frontoparietal central executive and default-mode networks in humans. Proc Natl Acad Sci U S A 110:19944-19949. CrossRef Medline

Chhatwal JP, Schultz AP, Johnson K, Benzinger TL, Jack C Jr, Ances BM, Sullivan CA, Salloway SP, Ringman JM, Koeppe RA, Marcus DS, Thompson P, Saykin AJ, Correia S, Schofield PR, Rowe CC, Fox NC, Brickman AM, Mayeux R, McDade E, et al. (2013) Impaired default network functional connectivity in autosomal dominant Alzheimer disease. Neurology 81:736-744. CrossRef Medline

Cho SS, Yoon EJ, Bang SA, Park HS, Kim YK, Strafella AP, Kim SE (2012) Metabolic changes of cerebrum by repetitive transcranial magnetic stimulation over lateral cerebellum: a study with FDG PET. Cerebellum 11: 739-748. CrossRef Medline 
Demirtas-Tatlidede A, Freitas C, Cromer JR, Safar L, Ongur D, Stone WS, Seidman LJ, Schmahmann JD, Pascual-Leone A (2010) Safety and proof of principle study of cerebellar vermal theta burst stimulation in refractory schizophrenia. Schizophr Res 124:91-100. CrossRef Medline

Demirtas-Tatlidede A, Freitas C, Pascual-Leone A, Schmahmann JD (2011) Modulatory effects of theta burst stimulation on cerebellar nonsomatic functions. Cerebellum 10:495-503. CrossRef Medline

Desmond JE, Chen SH, Shieh PB (2005) Cerebellar transcranial magnetic stimulation impairs verbal working memory. Ann Neurol 58:553-560. CrossRef Medline

Dobromyslin VI, Salat DH, Fortier CB, Leritz EC, Beckmann CF, Milberg WP, McGlinchey RE (2012) Distinct functional networks within the cerebellum and their relation to cortical systems assessed with independent component analysis. Neuroimage 60:2073-2085. CrossRef Medline

Eldaief MC, Halko MA, Buckner RL, Pascual-Leone A (2011) Transcranial magnetic stimulation modulates the brain's intrinsic activity in a frequency-dependent manner. Proc Natl Acad Sci U S A 108:2122921234. CrossRef Medline

Fox MD, Greicius M (2010) Clinical applications of resting state functional connectivity. Front Syst Neurosci 4:19. CrossRef Medline

Fox MD, Snyder AZ, Vincent JL, Corbetta M, Van Essen DC, Raichle ME (2005) The human brain is intrinsically organized into dynamic, anticorrelated functional networks. Proc Natl Acad Sci U S A 102:9673-9678. CrossRef Medline

Gratton C, Lee TG, Nomura EM, D'Esposito M (2013) The effect of thetaburst TMS on cognitive control networks measured with resting state fMRI. Front Syst Neurosci 7:124. CrossRef Medline

Grimaldi G, Argyropoulos GP, Boehringer A, Celnik P, Edwards MJ, Ferrucci R, Galea JM, Groiss SJ, Hiraoka K, Kassavetis P, Lesage E, Manto M, Miall RC, Priori A, Sadnicka A, Ugawa Y, Ziemann U (2014) Non-invasive cerebellar stimulation-a consensus paper. Cerebellum 13:121-138. CrossRef Medline

Habas C, Kamdar N, Nguyen D, Prater K, Beckmann CF, Menon V, Greicius MD (2009) Distinct cerebellar contributions to intrinsic connectivity networks. J Neurosci 29:8586-8594. CrossRef Medline

Halko MA, Eldaief MC, Horvath JC, Pascual-Leone A (2010) Combining transcranial magnetic stimulation and FMRI to examine the default mode network. J Vis Exp pii:2271. CrossRef Medline

Hashimoto M, Ohtsuka K (1995) Transcranial magnetic stimulation over the posterior cerebellum during visually guided saccades in man. Brain 118:1185-1193. CrossRef Medline

Huang YZ, Edwards MJ, Rounis E, Bhatia KP, Rothwell JC (2005) Theta burst stimulation of the human motor cortex. Neuron 45:201-206. CrossRef Medline

Koch G, Mori F, Marconi B, Codecà C, Pecchioli C, Salerno S, Torriero S, Lo Gerfo E, Mir P, Oliveri M, Caltagirone C (2008) Changes in intracortical circuits of the human motor cortex following theta burst stimulation of the lateral cerebellum. Clin Neurophysiol 119:2559-2569. CrossRef Medline

Krauzlis RJ, Miles FA (1998) Role of the oculomotor vermis in generating pursuit and saccades: effects of microstimulation. J Neurophysiol 80: 2046-2062. Medline

Krienen FM, Buckner RL (2009) Segregated fronto-cerebellar circuits revealed by intrinsic functional connectivity. Cereb Cortex 19:2485-2497. CrossRef Medline

Lu J, Liu H, Zhang M, Wang D, Cao Y, Ma Q, Rong D, Wang X, Buckner RL, Li K (2011) Focal pontine lesions provide evidence that intrinsic functional connectivity reflects polysynaptic anatomical pathways. J Neurosci 31:15065-15071. CrossRef Medline

O'Reardon JP, Solvason HB, Janicak PG, Sampson S, Isenberg KE, Nahas Z, McDonald WM, Avery D, Fitzgerald PB, Loo C, Demitrack MA, George MS, Sackeim HA (2007) Efficacy and safety of transcranial magnetic stimulation in the acute treatment of major depression: a multisite randomized controlled trial. Biol Psychiatry 62:1208-1216. CrossRef Medline

O'Reilly JX, Beckmann CF, Tomassini V, Ramnani N, Johansen-Berg H (2010) Distinct and overlapping functional zones in the cerebellum defined by resting state functional connectivity. Cereb Cortex 20:953-965. CrossRef Medline

Pascual-Leone A, Rubio B, Pallardó F, Catalá MD (1996) Rapid-rate trans- cranial magnetic stimulation of left dorsolateral prefrontal cortex in drugresistant depression. Lancet 348:233-237. CrossRef Medline

Pastor MA, Thut G, Pascual-Leone A (2006) Modulation of steady-state auditory evoked potentials by cerebellar rTMS. Exp Brain Res 175:702709. CrossRef Medline

Prevosto V, Graf W, Ugolini G (2010) Cerebellar inputs to intraparietal cortex areas LIP and MIP: functional frameworks for adaptive control of eye movements, reaching, and arm/eye/head movement coordination. Cereb Cortex 20:214-228. CrossRef Medline

Raichle ME, MacLeod AM, Snyder AZ, Powers WJ, Gusnard DA, Shulman GL (2001) A default mode of brain function. Proc Natl Acad Sci U S A 98:676-682. CrossRef Medline

Robinson FR, Fuchs AF (2001) The role of the cerebellum in voluntary eye movements. Annu Rev Neurosci 24:981-1004. CrossRef Medline

Schmahmann JD (1991) An emerging concept. The cerebellar contribution to higher function. Arch Neurol 48:1178-1187. CrossRef Medline

Schmahmann JD (2004) Disorders of the cerebellum: ataxia, dysmetria of thought, and the cerebellar cognitive affective syndrome. J Neuropsychiatry Clin Neurosci 16:367-378. CrossRef Medline

Schmahmann JD, Pandya DN (1997) The cerebrocerebellar system. Int Rev Neurobiol 41:31-60. CrossRef Medline

Schmahmann JD, Sherman JC (1998) The cerebellar cognitive affective syndrome. Brain 121:561-579. CrossRef Medline

Schmahmann JD, Doyon J, Toga AW, Petrides M, Evans AC (2000) MRI atlas of the human cerebellum. San Diego: Academic.

Sheline YI, Raichle ME (2013) Resting state functional connectivity in preclinical Alzheimer's disease. Biol Psychiatry 74:340-347. CrossRef Medline

Snider R, Eldred E (1951) Electro-anatomical studies on cerebro-cerebellar connections in the cat. J Comp Neurol 95:1-16. CrossRef Medline

Snider RS (1950) Recent contributions to the anatomy and physiology of the cerebellum. Arch Neurol Psychiatry 64:196-219. CrossRef Medline

Snider RS, Stowell A (1946) A comparison of the tactile areas in the cerebellum of the cat and monkey (Macaca mulatta). Anat Rec 94:498. Medline

Sperling RA, Laviolette PS, O'Keefe K, O’Brien J, Rentz DM, Pihlajamaki M, Marshall G, Hyman BT, Selkoe DJ, Hedden T, Buckner RL, Becker JA, Johnson KA (2009) Amyloid deposition is associated with impaired default network function in older persons without dementia. Neuron 63 : 178-188. CrossRef Medline

Stoodley CJ, Valera EM, Schmahmann JD (2010) An fMRI study of intraindividual functional topography in the human cerebellum. Behav Neurol 23:65-79. CrossRef Medline

Strick PL, Dum RP, Fiez JA (2009) Cerebellum and nonmotor function. Annu Rev Neurosci 32:413-434. CrossRef Medline

Théoret H, Haque J, Pascual-Leone A (2001) Increased variability of paced finger tapping accuracy following repetitive magnetic stimulation of the cerebellum in humans. Neurosci Lett 306:29-32. CrossRef Medline

van der Werf YD, Sanz-Arigita EJ, Menning S, van den Heuvel OA (2010) Modulating spontaneous brain activity using repetitive transcranial magnetic stimulation. BMC Neurosci 11:145. CrossRef Medline

Vercammen A, Knegtering H, den Boer JA, Liemburg EJ, Aleman A (2010) Auditory hallucinations in schizophrenia are associated with reduced functional connectivity of the temporo-parietal area. Biol Psychiatry 67: 912-918. CrossRef Medline

Voogd J, Schraa-Tam CK, van der Geest JN, De Zeeuw CI (2012) Visuomotor cerebellum in human and nonhuman primates. Cerebellum 11:392410. CrossRef Medline

Watanabe T, Hanajima R, Shirota Y, Ohminami S, Tsutsumi R, Terao Y, Ugawa Y, Hirose S, Miyashita Y, Konishi S, Kunimatsu A, Ohtomo K (2014) Bidirectional effects on interhemispheric resting-state functional connectivity induced by excitatory and inhibitory repetitive transcranial magnetic stimulation. Hum Brain Mapp 35:1896-1905. CrossRef Medline

Yeo BT, Krienen FM, Sepulcre J, Sabuncu MR, Lashkari D, Hollinshead M, Roffman JL, Smoller JW, Zöllei L, Polimeni JR, Fischl B, Liu H, Buckner RL (2011) The organization of the human cerebral cortex estimated by intrinsic functional connectivity. J Neurophysiol 106:1125-1165. CrossRef Medline

Zhang D, Raichle ME (2010) Disease and the brain's dark energy. Nat Rev Neurol 6:15-28. CrossRef Medline 